\title{
Understanding the Communication Pattern and Emotional Abuse:Domestic Violence Victims Among Married Women
}

\author{
Muhammad Shahidan Shaari, Mohd Haizzan Yahaya, Nurul Jannah Mohd Juaini
}

\begin{abstract}
This study aims to understand the verbal and non-verbal communication patterns and emotional abuse that ensued married women in Penang, Malaysia. It has been conducted with the involvement of ten respected respondents. Qualitative research approach with in-depth interview has taken place in this study. The findings revealed that there are two types of verbal languages, reactions or words that could cause emotional and psychological abuse. First, dishonour and disgraces words or languages and the second one are the expression of criticism and negative thought. Meanwhile, the economic difficulties, incapable in fulfilling sexual desire, concept of minimizing, blaming and lack of attention, love and care and cheating and disrespect their dignity were the consequences of non-verbal communication which led to emotional and psychological abuse. Improvement and amendment in Domestic Violence Act (1994) as an early prevention and execution has been suggested in this study to minimize the increasing number of emotional abuse victims in married women in Penang, Malaysia.
\end{abstract}

Index Terms:- Communication pattern, domestic violence, emotional abuse, psychological abuse.

\section{INTRODUCTION}

Communication is one of the social interaction aspects that are dynamic and give a huge impact on changing the attitude of an individual [1]. Communication that occurs in daily life is to explain about feelings, situation, and thinking in order to give the understanding to the receiver by using symbols or languages [2].

There are two types in communication aspects. The first one is verbal aspect. Verbal aspect involved the term of talking and by using words to send information, express feelings, perceptions and deniable about something. For example, some of the individual's emotion can be understood by examine at her or his intonation of the voice and the type of languages or words that has been used. Meanwhile, the non-verbal aspects of communication involve body movement, face expression, physiological reaction and the change of emotion and attitude itself [3]. In addition, in [4] have listed more examples of non-verbal communications such as touching, clothing, personal space, territoriality, voice, physical appearance, and the environment.

For some reasons, study has shown that verbal and nonverbal aspects of communications between male and female

Muhammad Shahidan Shaari, School of Social Sciences, Universiti Sains Malaysia, 11800 Pulau Pinang, Malaysia.

Mohd Haizzan Yahaya, School of Social Sciences, Universiti Sains Malaysia, 11800 Pulau Pinang, Malaysia.

Nurul Jannah Mohd Juaini, Faculty of Applied Social Sciences, Universiti Sultan Zainal Abidin, Gong Badak Campus, 21300 Kuala Nerus, Terengganu, Malaysia.
Revised Manuscript Received on July 10, 2019.

partner may cause psychological and emotional abuse if it's delivered in negative way and women often on becoming the victims of it [5]. In fact, a research by [6] found that women tend to be the victims of domestic abuse because they basically use violence in self defend or when they fear being attacked, otherwise men are likely to use violence as a means of control or when their dominance character and power has been challenged.

Meanwhile, in [5] has explains that emotional abuse can be viewed as the non-physical abuse of a partner that take place over a period of time, in which the abuser or male partner systematically diminishes and destroyers the inner self of his victims or female partner either overtly or covertly. This is done to gain control within the relationship and coerce his victim into subservience to maintain his control over her behaviour.

From this statement, if we look at the Malaysian situation and perspectives, it is true that almost all married couple are practicing complementary relationships that put the authority on leading the family and decision making to men until sometimes women become powerless and dependence [7].

\section{A. Emotional Abuse Issues and Difficulties through Malaysian Society}

According to the Annual Report in 2016 [8], it has shown from 111 victims of domestic violence women that has been taken all over the states in Malaysia, and is registered under this organization, also known as survivors, the number of 99 victims or almost $89 \%$ of them involved in emotional or psychological abuse. Here means where although emotional abuse does not involved with any physical injure but it will leave a negative impact on internal and external development of woman's life.

In Malaysian, in [9] explain that Ministry of Women, Family and Community Development had gave their attention on this issue due to receiving lots of reports by the victims among women and their family members about several cases involving emotionally and psychologically threatened from their married partner. Alternative action by the ministry agreed to come out with a solution by having minor amendment on the term of 'Keganasan Rumah Tangga' in Domestic Violence Act (1994), Act 521. The amendment took place as follows:

1. Section 2(f) causing psychological abuse which includes emotional injury to the victims; 

VICTIMS AMONG MARRIED WOMEN

2. Section $2(\mathrm{~g})$ causing the victims to suffer delusions by using any intoxicating substance or any other substance without the victim's consent or if the consent is given, the consent was unlawfully obtained; or

3. Section $2(\mathrm{~h})$ in the case where the victim is a child, causing the victim to suffer delusions by using any intoxicating substance or any other substance, by a person, whether by himself or through a third party, against:

(i) his or her spouse;

(ii) his or her former spouse;

(iii) a child;

(iv) an incapacitated adult; or

(v) any other member of the family;

Meanwhile, the problem is there are no specific explanations about the form or the constitution of emotional and psychological abuse that can convict or to declare someone guilty by the judiciary system. Nevertheless, this act also does not have any systematic and proper classification and characterization about emotional or psychological abuse that may occurs in many ways and factors especially from the aspects of non-verbal communication. According to [10], the focus is more on physical abuse or injury as this kind of abuse is proved by the biological appearance or condition after observing its sign by Medical Report at time the physical abuse cases is brought to the court. For example, wounds, signs of burning, or broken bones.

As a matter of fact, the legal arresting of an offender only can be discharged by the court when the offender is really hurting the defender physically along with the specific duration of time that has been stated or also known as Interim Protection Order (IPO). It is not fair because for the emotional abuse problem, some of the cases are grim to diagnose if it is still in the early phase. Moreover, emotional abuse cannot be seen by eyes to prove it and can easily being denial [11]. In [12] mentioned that it is only can be recognized by the expression of the feelings, attitude and physiological response by the victims.

However, until the symptoms of mental illness, clinical depression, rebellion, aggressive behaviour or suicide had occurred among the victims, then the report will be made and finally the authority will start to take a serious action to this matter. In [13] stated that when a woman is being called by using negative words like "bodoh" and "hodoh", they feel so discreditable but do not think it is an emotional abuse issue. They also do not seek for treatment and help or to take any action. It is because they do not know about the existence of the act on emotional and psychological abuse also has less lack of knowledge and information about it [10].

\section{B. Linkage between Communication Pattern and Emotional Abuse (Cycle of Abuse Theory)}

This theory is developed to describe the patterns of behaviour in an abusive relationship. There are four phases in cycle of abuse. The first phase is known as Tension Building. At this phase, the concept of stress and pressures exist. It occurs in many ways for instance by the children, other family members, confusion, and financial problem. At this phase, for the victims, they will become passive, fear, complaisant and foster as a tactics to avoid from being violated by their partner or husband that feel angry, annoyed and ignored [14]. This feeling can last for few minutes to several hours and maybe for some months. The abuser basically will attack the victims by using curse words, bad language and accusation.

Second phase is Acute Violence. In this phase, the tension rising by reaching the maximum level and end up with violence [14]. The verbal abuse and emotional abuse will take at the first place then the abuser or husband will start to conquer their partner or the victims with domestic violence. At this phase, physical abuse, sexual abuse or maybe serious injury will happen to the victims.

Third phase explained as Honeymoon Phase or Reconciliation. At this phase, the abuser become so forgiving, caring and feel guilty of what happen. The abuser also feels afraid if their wife or the victims will leave and make a police report. But for the victims, they will feel confuse, sorrow, torture, scare and embarrass. Then, the abuser tries to seek for forgiveness from the victims and make a promise it will never happen again and may feel sadness [14]. The abuser will also try to obtain sympathy and persuade the victims to accept him back and not to end the relationship. The victims will start to believe and think that this is the best way or best time to fix and improve back the relationship with their husband as normal.

Forth phase is Calm. This phase is the extension of the Honeymoon phase. At this phase, the relationship between the abuser and the victims become stable, peaceful and smooth. But then, in a certain period of time, unpredictable and unpreventable conflict and tension will start to rise up again and then it is turning back to the first phase again [14]. The process of the cycle is shown in Fig. 1.

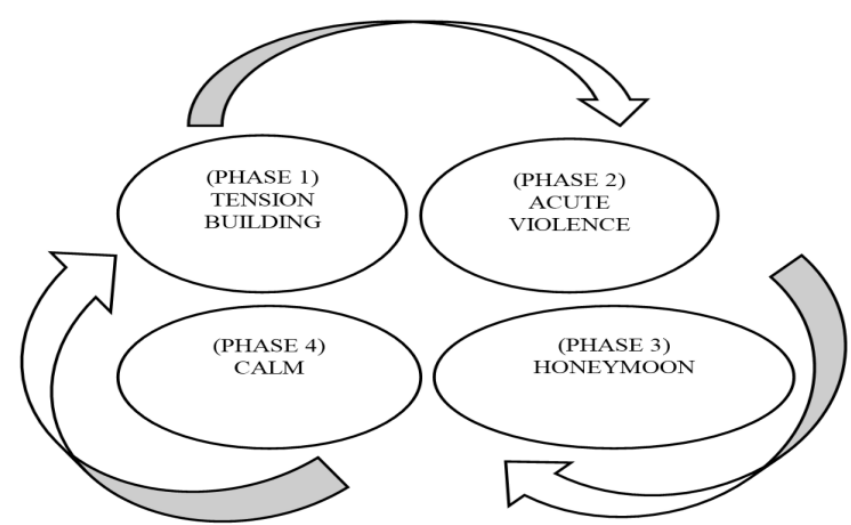

Fig. 1: Cycle of abuse theory [14]

\section{METHODOLOGY}

This research was conducted in Seberang Perai Utara, Penang, Malaysia by applying the qualitative research framework. The data gathered throughout in-depth interview. Purposive sampling method took place during the interview sessions. The respondents include the victims of the domestic violence at one of the NGO's in Kepala Batas, Penang. In order to obtain reliable data, the researchers

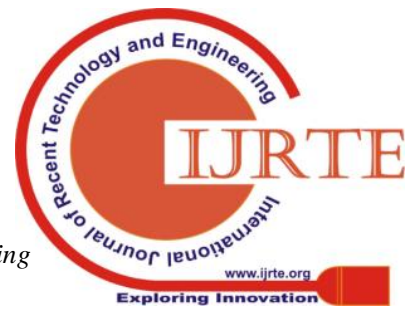


asked each participant to provide the researcher reference of who can be another source of information, and this process continue by using snowball sampling techniques. This method was chosen in order to obtain full information until the researchers attempt of data saturation.

\section{RESULTS AND ANLYSIS}

This research had formed three main themes. First theme is on classification of verbal and non-verbal language or reactions which used by the victim's partner that might leave negative impacts on their emotions and feeling. There were two types of verbal languages, reactions or words that would cause emotional and psychological abuse. The first one is dishonour and disgrace words or languages and the second one is the expression of criticism and negative thought.

Besides, there were four categories of non-verbal language or reactions that might led to emotional and psychological abuse. The first categories were economic difficulties, the second categories were incapable to fulfil sexual desire, and the third one was the concept of minimizing, blaming and less lack of attention, love and care. Meanwhile, the forth one was cheating and disrespect their dignity or symbolic violence.

The second theme was about the interpretation of the emotional and psychological abuse effects on the victims. The result stood up with most of them provide different answer of what had been happen and the most obvious things that effect their emotion were the feeling of sadness, gloom, despair and miserable. Some of the victim's also experiencing somatic problem.

The third theme is on the clarification of the victim's reaction, action and knowledge towards emotional and psychological abuse issues. The result shows that $100 \%$ of the respondents informed and notified someone about their problem. Unfortunately, only $40 \%$ of the respondents made report to the authority. Meanwhile, almost $60 \%$ of them did not make any reports or complaints. Throughout the survey, $100 \%$ of the respondents aware on the existing law and act on domestic abuse issues.

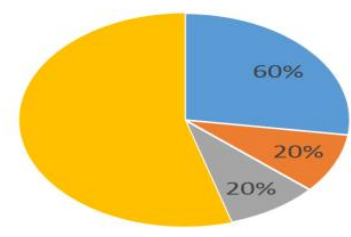

\footnotetext{
- Dishonour and Disgrace

- Criticize and Negative Thought

- Never Experience
}

Fig. 2: The percentage of verbal languages, words or reactions used by respondent's partner

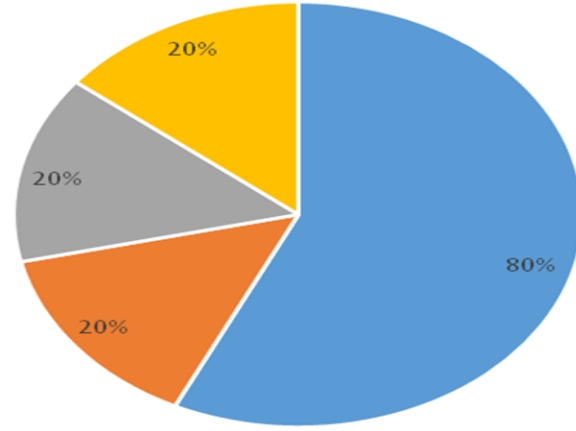

- Economic Difficulties

- Incapable to fulfill sexual desire

- The concept of minimizing, blaming and

less lack of attention, love and care

Fig. 3: The percentage of non-verbal languages or reactions used by their partner

\section{DISCUSSION}

There are three main themes, and first would begin with classification of verbal and non-verbal language or reactions that had been used by the victim's partner that might leave negatives impacts on their emotions and feeling. The second theme is on the interpretation of the emotional and psychological abuse effects on the victims. While, third theme emphases on the clarification of the victim's reaction, action and knowledge towards emotional and psychological abuse issues.

\section{A. Theme 1: Classification of Verbal and Non-Verbal Language}

From the findings, it shows that being contempt, despised, dishonour, disgrace and disrespect with some certain sentences or words were the type of verbal communication or reactions that leaved negatives impact and might led to emotional abuse issues. Besides that, most common verbal languages or reactions that frequently used by the abuser or victim's partner involved dishonour and disgrace words. From the findings, effective communication skills or patterns were the most important aspect in married and relationship. To maintain the term of homeostasis in family, it is very important for both partner to practice and to create feeling of understanding, sense of belonging, caring, motivating each other and always respect their dignity or honour [15].

Meanwhile, the researchers had discovered some new categories for non-verbal communications or reactions that also might cause emotional abuse, these were economic difficulties and incapable to fulfil sexual desire. Good management skills in financial, having systematic ways to spend money and know how to differentiate between family necessity and self needs would produce productive result on handling economic situation in married [16]. On the other hand, a study by [17] stated sexual activities were associated with the well-being, life satisfaction and happiness. Besides 


\section{UNDERSTANDING THE COMMUNICATION PATTERN AND EMOTIONAL ABUSE:DOMESTIC VIOLENCE VICTIMS AMONG MARRIED WOMEN}

that, the researchers also founded that one characteristic that could be added for the symbolic violence concept was cheating and disrespect their dignity with some terrible action or attitude as what had been happened to the one of the respondent throughout the interview session, when her husband brought his affair into their house and slept with her.

Next, another non-verbal reactions or languages that caused emotional abuse are the concept of minimizing and blaming. The findings also found that lack of attention, love and care was also the non-verbal languages or reaction that caused emotional abuse and this result fixed with other research that stated does not give freedom or too rigid in a relationship were the cause of emotional abuse [13].

\section{B. Theme 2: The Interpretation of the Emotional and Psychological Abuse Effects}

This research had shown that there were several effects of emotional abuse among the victims. The major effects of emotional abuse were minor depression and stressful. Besides that, fatigue was also some of the effects of emotional abuse. By this, victims were facing with lack of concentration, performance and had a low motivational capacity whether on working or in their daily life routine.

Besides, emotional abuse was also a long-term unstable condition and would result with serious illness or negative impact if it happened perpetually without being treated and controlled. Some of the victims that managed to cope out had a huge potential on becoming aggressive and involved in deviant behaviour but some who were failed to adapt with the difficulties would face with clinical depression, hopeless in life which mean chanced to commit suicide or encounter with mental illness were greater. This result consistence with previous research that described emotional abuse was like a brainwashing that was systematically decreasing victim's self-concept and the sense of self-worth which would lead to more serious issue when it started to effect on victim's mental to think wisely and normally [18].

On the other hand, another common effect of emotional abuse that could happen abruptly was extreme feelings of sadness. Referring to [19], the excessive feelings of sadness that happened to someone was much related with another biological, psychological and social functioning affects such as insomnia, isolation, lack of appetite and energy. It gave clear viewed that emotional abuse was a painful event for every woman in their life experience.

\section{Theme 3: The Clarification of the Victim's Reaction, Action and Knowledge}

Researchers found that all the victims knew about the existing law or act according to physical abuse issue but did not have any cleared vision or thought regarding on emotional and psychological abuse issues. It was proved when the victims told the researchers that if they were being physically injured or hurt by their partner, so they can surely make a report, but did not know or confused if they could still submit any report or complaint if they were being threatened emotionally or psychologically. It was because they were worried if they could not have prepared with concrete evident for the legal practitioner as references.

Some of the victims suggested that the scope of the domestic abuse act or law should be wider and comprehensive because it could happen in various ways and still would leave negative impacts, tension and pressure to the victims. This result was almost the same as what had been explained by [20] whom stated victims also believes people will not take that kind of assault experiences as serious issue or maybe will blame them back for what happen because they do not have any prove to convince the law.

Meanwhile, there were no cleared evident could be related from this research to support the facts by [21] that mentioned the victims of emotional abuse basically did not make any report or seek for help because the sense of fear they might being attacked physically by their abusive partner. Apart from that, the researcher revealed some of the reasons on why the victims did not took any action or report was because they were so afraid of suffering from loss of shelter and protection to survive in their daily life.

For the next findings, it resulted all the victims expressed and told their problem to someone close to them and could be trusted whether their family members, neighbours, friends and in facts, their own husband. It was an excellent practiced in order to relief of the tension and not only that, it could also enhance the self-esteem of an individual [22].

\section{Implication to Social Work Practice}

Social workers will play some of the important role concerning to this problem. Start with relieve the tension rising among the victims until the phase of advocacy for them to serve a better service and protect to their rights. That is what social worker always does. As a result, that has been shown in this research, there is a few ways in intervention with all the clients.

First, social worker should gather information's from the victims as much as they could to make sure social justice as the main priority. A comprehensive and full of diversity on documentation are important to minimize bureaucracy and other factors that may affect the prosecution process.

Toward this, social workers must also prepare concrete and correct knowledge, understanding and information about the law and the act involve, the rule and regulation so do the term and condition to counter back with this serious problem wisely and comprehensively for an advocacy action in court.

Next, due to most of the victims do not realize on their real condition when it comes in to understand and analyse their own emotion and feelings, social worker must be alert with any sign or symptom of depression, mental illness or any abnormal psychology that shown by the clients. This is important in making sure social worker react on early prevention action by referring the clients to the expert. As a social worker, the role of broker and educator can take place to help them dealing with their problem [4].

Finally, most of the victims seems refuse to speak out or share on what they have gone through in their life especially related to domestic violence. In this, social worker need to 
act creative and innovative to find best ways to make sure their clients explain and speak out on their problem. A good communication skill, impression and expression are the key to be practicing from the beginning until the end of the interview session. Social worker can play the role as an enabler and facilitator to make sure these methods can be sustained over time for their own improvement [4].

\section{CONCLUSION}

Improvement in Domestic Violence Act is critically needed due to the emotional and psychological abuse cases. The mentioned act must aim to spread and advocate for a betterment of women whom live with emotional and psychological pressurize. By strengthening this Act through some of new conceptualization and locution referring to emotional and psychological abuse causes and effects, it may help to tackle the complexity, bureaucracy and the diversity of this problem [8].

Self-high motivation is very important by not to reminisce and not feel afraid to acquiesce or make any report and seek for help from the authority before this problem getting more worst in any relationship. Good support system is needed when handling with this issue. Religious institution can be as one of the best support system where can provide a great deal of services such as counselling session, short term of financial support, build the inner strength of the victims with spiritual activities and conduct awareness program, courses and motivational speech concerning to this issue. Some of the religious institutions may also have its own trauma centre that can assist in assembling such support groups, if they do not already exist [5].

In this new era of globalization, mass media, electronic media and social media can take part to play an important role together by providing and share information regarding to these issues. For example, social media such as Facebook and Whatsapp are good platform in promoting and advertising about this delinquent. Experts like social worker, lawyer, counsellor, police and NGO's worldwide should take this opportunity and advantages to educate people with a lot of matters regarding to domestic abuse issues. Coping strategies on preventing domestic abuse provide some knowledge to people about the existing law and how to take an action should be addressed. This is because most of the victims do not have any clear view, knowledge and information about their rights and what is the best solution where they can take to protect themselves.

\section{REFERENCES}

1. H. Northen, "Communication and interaction patterns," in An Introduction to Group Work Practice, R. W. Toseland and R. F. Rivas, Eds. England: Pearson, 2017, pp. 84-94.

2. R. W. Toseland, and R. F. Rivas, An Introduction to Group Work Practice. England: Pearson, 2017.

3. G. Westland, Verbal and Non-Verbal Communication in Psychotherapy. New York: W. W. Norton and Company, 2015.

4. C. H. Zastrow, and K. K. Kirst-Ashman, Understanding Human Behavior and Social Environment. Boston: Cengage Learning, 2010.

5. M. Barkhuizen, Professional Women as Victims of Emotional Abuse within Marriage or Cohabitating
Relationships: A Victimologial Study. Gauteng: University of Pretoria, 2004.

6. C. M. Renziti, and D. J. Curran, Women, Men, and Society. Boston: Allyn and Bacon, 2003.

7. R. H. Price, and P. E. Politser, Evaluation and Action in the Social Environment. London: Academic Press, 2014.

8. Penang Women's Development Corporation (PWDC), Realising equality together: 2016 annual report. Penang: PWDC, 2016.

9. F. Arof, Awas si pendera emosi isteri Available: http://ww1.utusan.com.my/utusan/info.asp?y=2011\&dt $=0629 \&$ pub=Utusan_Malaysia\&sec $=$ Rencana\&pg $=$ re 05.html.

10. N. Dandavati, Perspektif keganasan rumah tangga. Selangor: Pertubuhan Pertolongan Wanita (WAO), 2017.

11. G. L. Jantz, Hope and healing from emotional abuse. Minnesota: Aspire, 2013.

12. N. S. Ahmad, Mangsa Dera Seksual. Pulau Pinang: Universiti Sains Malaysia, 2012.

13. R. Jacob, "Wanita dan ketenangan jiwa," in Malaysia Isu-Isu Sosial Semasa, R. Omar and S. Pandian, Eds. Kuala Lumpur: Institut Sosial Malaysia, 2005.

14. L. E. Walker, Battered Woman Syndrome. New York: Springer Publishing Company, 2009.

15. D. Collins, C. Jordan, and H. Coleman, An Introduction to Family Social Work. Boston: Cengage Learning, 2009.

16. L. J. Gitman, M. D. Joehnk, and R. Billingsley, Personal Financing Planning. Boston: Cengage Learning, 2013.

17. A. Muise, U. Schimmack, and E. A. Impett, "Sexual frequency predicts greater well-being, but more is not always better," Journal of Social Psychological and Personality Science, 7(4), 2016, pp. 295-302.

18. B. Engel, The Emotionally Abusive Relationship. New Jersey: John Wiley and Sons, 2002

19. A. V. Horwitz, and J. C. Wakefield, The Loss of Sadness. New York: Oxford University Press, 2007.

20. J. L. Postmus, Sexual Violence and Abuse: An Encyclopedia of Prevention, Impacts and Recovery. California: ABC-CLIO, 2012.

21. M. C. Henry, and E. R. Stapleton, EMT Prehospital Care. Massachusetts: Johns and Bartlett Publishers, 2011.

22. T. Looker, Manage Stress for a Happier Life: Teach Yourself. London: Hachette, 2011. 